\title{
Design of Remote Monitoring and Control System with Automatic Irrigation System using GSM-Bluetooth
}

\author{
Purnima, S.R.N. Reddy, PhD. \\ Department of Electronics \& Communication \& Computer Science \\ IGIT, GGSIP University, Delhi, India
}

\begin{abstract}
In past few years, automatic irrigation system has seen a rapid growth in terms of technology. At present cost-saving technology, labor-saving are the addressing key issues in irrigation. This paper gives a review of these systems based on existing technologies and also proposes an economical and generic automatic irrigation system based on wireless sensors with GSM-Bluetooth for irrigation system controller and remote monitoring system. This system has simpler features designed with the objective of low cost and effective with less power consumption using sensors for remote monitoring and controlling devices which are controlled via SMS using a GSM module. A Bluetooth module is also interfaced with the main microcontroller chip. This Bluetooth module eliminates the usage charges by communicating with the appliances via Bluetooth when the application is in a limited range of few meters. The system informs user about any abnormal conditions like less moisture content and temperature rise, even concentration of $\mathrm{CO} 2$ via SMS from the GSM module or by Bluetooth module to the farmer's mobile and actions are taken accordingly by the farmer. In future, the farmer will be able to monitor and control the parameter by GSM and Bluetooth technologies.
\end{abstract}

\section{Keyword}

GSM, Bluetooth, remote monitoring, Sensors, Microcontroller, Agriculture

\section{INTRODUCTION}

Wireless technology for an intelligent irrigation system has become a popular research with the greenhouse effect. People are utilizing the merits of embedded system into monitoring and control system for an intelligent irrigation system because of lots of advantages. For many, the term 'wireless' is daunting because it brings forth a whole lexicon of additional terms and acronyms such as WiFi, ZigBee, RFID, WLAN, Bluetooth and 802.11x that

are new and intimidating. Monitoring parameters of temperature and humidity is an important means for obtaining high-quality environment. Remote monitoring is an effective method in order to avoid interference environment and improve efficiency. Today, Ethernet network, RF module and zigbee wireless network are used to transmit data in remote Monitoring System. A wireless solution for intelligent field irrigation system dedicated to Jew'sear planting in Lishui, Zhejiang, China, based on ZigBee technology was proposed by Yiming Zhou [1]. Zigbee is wireless network with special agreement. It is high costs, hard to be developed and limited signal coverage. While WSN dispenses with the substantial costs of wiring, the Zigbee WSN technologies are most suitable for agriculture applications comparing with Wi-Fi and Bluetooth.

Highly robustness for the interferences has made Bluetooth as a highly versatile and attractive technology among other short range wireless technologies. Operating over unlicensed, globally available frequency of $2.4 \mathrm{GHz}$, it can link digital devices within a range of $10 \mathrm{~m}$ to $100 \mathrm{~m}$ at the speed of up to $3 \mathrm{Mbps}$ depending on the Bluetooth device class.

This paper gives a review of remote control and monitoring systems based on existing technologies and a GSM-Bluetooth based remote control and monitoring system with automatic irrigation system is proposed.

The design presented has the advantage of both GSM and Bluetooth technology and the sensors and devices are controlled by both by using Bluetooth when in a limited range with the appliances and using SMS for remote monitoring and control thereby reducing the usage charges of GSM.

The rest of the paper is organized as follows. Section II gives the classification of generic remote control systems based on technology and processors used and applications of the systems. Section III analyzes the existing systems; Section IV describes the proposed systemFinally Section V concludes the references papers.

\section{II.CLASSIFICATION OF GENERIC REMOTE CONTROL SYSTEMS}

The idea of remotely controlling and monitoring of irrigation system and acquisition of weather related information is flourishing day by day with the use of latest technologies. There are many types of remote control and monitoring systems available. These systems are typically designed and installed for different purposes.

The prime objectives of new wireless generation agriculture system are :

\section{Remote monitoring}

- Data from gauges and sensors (soil moisture, pressure, environmental, etc.)

- Status of farm gates and building doors (open/close)

- Status of irrigation valves

- $\quad$ status of pumping equipment

- Video of operation in live mode

- Monitoring of greenhouses, livestock enclosures, and storage facilities

- Audible or other alarms

\section{Remote control}

- Opening and closing valves \& gates

- Turning on and off fans, lights, pumps, heaters, etc,

- Guiding robotic vehicles, if used 


\section{Information transfer}

- Automatic incorporation of environmental data into decision support systems and crop models

- Uploading maps to variable rate application equipment

- Weather, market, \& operational information to remote locations \& vehicles

- Real-time information such as DGPS correction signals

\section{Communication}

- Text, graphical, voice and video messages can be sent between peoples

\section{Asset tracking}

- Position of irrigation systems

- $\quad$ Location of farm vehicles

- $\quad$ Location of livestock

Different technologies used for designing these remote control and monitoring systems have been studied [2] - [23]. From technical point of view these systems can be classified on the basis of Technology and applications \& processors used. Table 1 shows the classification of existing systems based upon different criteria.

\section{Technology Used and Applications}

Shen Jin, Song Jingling, Han Qiuyan, Wang Shengde introduced a GSM-SMS remote measurement and control system for greenhouse [2] based on PC-based database system connected with base station. Base station is developed by using a microcontroller, GSM module, sensors and actuators. In practical operation, the central station receives and sends messages through GSM module. Criterion value of parameters to be measured in every base station is set by central station, and then in base stations parameters including the air temperature, the air humidity. Modularization is adopted in the design of the system hardware, and the software exploitation is realized by embedded operating system, all of which make the system easy to be extended maintained and transplanted.

[3] proposed an example of the enhancement of the photovoltaic pumping system efficiency depends on the optimization of the photovoltaic energy generation and the system consumption. This paper presents an optimally designed and realized photovoltaic pumping system which can be used for irrigation, under the variation of climate conditions, in the remote area, far away from national electric grid, of Batna region in Algeria. The photovoltaic pumping system is built at the laboratory level and the first tests of the control parts have showed very promising results. G. K. Banerjee and Rahul Singhal et. al. [4] proposed a method using microcontroller for the control of temperature and relative humidity inside a poly house. In the proposed method, the greenhouse controller senses the change in temperature and relative humidity with the help of input sensors and process the output to take appropriate control action. The proposed system is a low cost and user friendly system with high stability and reliability.

[5] proposed the automation of a free-standing greenhouse using supervisory control $\&$ data acquisition (SCADA) system. The end product is expected to give the farmer or end user a kiosk type approach. Entire greenhouse operation will be governed and monitored using this kiosk. This approach is fairly novel considering the unified system design and the SCADA platform, NI LabVIEW 7.1. Wi-Fi technology is also explained in [6]. It introduces a wireless sensor network (WSN) used for an intelligent temperature measurement system. In the system, temperature signals are acquired by digital multipoint thermometers, and transmitted to the advanced RISC microprocessor (ARM) by using Wireless Fidelity (WiFi) technology. Then they are stored in SD card which is controlled by the microprocessor according to the IIS-bus standard format. The software design of data acquisition is completed in this paper. The progress of transplanting Linux operating system to the ARM hardware platform is described, and the driver programs of SD card and SD WiFi device are developed based on Linux operating system and SD card agreement. A special data storage file system is accomplished for reading and writing SD card, as well as managing of the data file by the FAT16 file system. At last, the function of man-machine interaction is accomplished.

To provide more knowledge and a comparative view, Newe, T. and Lewis, E. [7] proposed a Wireless Sensor based review paper. Wireless sensor networks (WSN) are becoming increasingly popular, due to the benefits they bring to many applications as well as the increasing availability and maturity of the underlying technology. The fundamental building blocks of these networks are the sensor nodes themselves, the sensors attached to these nodes, and the software running on the nodes. A basic sensor node platform consists of a CPU, a radio and a power supply. A similar system for remote monitoring and controlling system is described in [8]. Ahmed, V. et. al. proposed the development of innovative low cost cell phone based remote control application for induction motor-pump based irrigation in agriculture. Rural areas in many states of India are affected by frequent power cuts and abnormal voltage conditions. The developed system ensures that water is distributed to field whenever normal conditions exist based on task specified. A novel concept of miscall for specified duration has been used to reduce the operational cost of the system and for the convenience of farmers facing difficulty in typing messages. Information is exchanged in form of miscalls / message between the system and the user cell phones. The system used AVR ATMEGA32 microcontroller and includes features like protection against single phasing, over-current, dry running.

[9] proposed the development of generic ultra-low cost remote control application based on cell phone for induction motorpump based irrigation in agriculture. In mostly rural areas within states of India are affected by frequent power cuts and abnormal voltage conditions. The developed system ensures that water is distributed to field whenever normal conditions exist based on task specified. The task is initially specified through keyboard / SMS. A generous concept of number of miscalls in specified duration has been used to reduce the operational cost of the system to bare minimum. Information is exchanged in form of messages / miscalls between the system and the user cell phones. The system is based on AVR ATMega32 micro-controller and includes protection against single phasing, over-current, dry running and other desirable features. RTC DS1307 and DS18S20 are used for time and temperature measurement respectively. It is expected that system will relieve hardships of farmers relating water distribution to a great extent.

In [10] describes the concept of sensor networks which has been made viable by the convergence of micro-electro-mechanical systems technology, wireless communications and digital electronics. First, the sensing tasks and the potential sensor networks applications are explored, and a review of factors influencing the design of sensor networks is provided. Communication architecture for sensor networks is configured, and the algorithms and protocols developed for each layer in the 


\section{literature are explored.}

Mahir Dursun and Semih Ozden [11] proposed a prototype of solar powered, low cost, remote controlled real time monitoring irrigation system was designed to control drip irrigation. Software (ValCon, developed by authors with $\mathrm{C}$ language in Visual Studio.Net 2008 editor) was developed to control irrigation valve and monitor water content of soil. Users can select control method of irrigation (automatic or manual). Only water content of soil was monitored. Nevertheless by using sensors which measure other features of water or air, it is also possible to extend the designed system. Remote controlled site-specific irrigation scheme prevents moisture stress of trees and salification besides providing the efficient use of fresh water resources. Also, this irrigation method removes labour that is needed for flooding irrigation. In [12], A greenhouse carbon dioxide concentration measurement and control system is designed based on fuzzy control with infrared carbon dioxide gas sensor, and the choice of the control structure parameters are given. According to the experience, the main points of the design of control rules are induced, and the carbon dioxide concentration fuzzy controller is constructed with relevant fuzzy logic. The modular structure is used for system hardware and software design, enhance the versatility and flexibility of the use of system. The application shows that the $\mathrm{CO} 2$ measurement and control system achieved using fuzzy control is running stable, fast response, has broad application prospects.

The system in [13] proposes Remote Monitoring and control Systems based on GSM. GSM network is a medium for transmitting the remote signal and communication takes place between monitoring centre and remote monitoring station. The central monitoring station performs real time control, alarm and data processing and also manages database. Receiving and sending of the data in the central monitoring station is achieved by using the GSM wireless communications module TC35 in [13]. TC35 is introduced by SIEMENS which is a dedicated Modem. GSM module is interfaced using RS232 and accessed using AT commands. [14] introduced GPRS technology with better application prospect. The sensor node gathers the hydrographic information such as water-level, gate position and rainfall. The sink node receives the real-time data; the information centre stores and processes those data which are transmitted from the sink node through the GPRS network. The system replaces the wired transmission with the wireless transmission, which reduces the costs in installment and maintenance, and improves the system's reliability and extension.

A Low cost soil moisture monitoring system is explained in [15]. The paper describes a PC controlled irrigation monitoring and controlling system with wireless communication. The design of the overall system is based on: the system must provide consistent soil moisture measurements at low cost; the system must interface with an irrigation system to allow for automatic watering of the soil; and the measurement units must be unobtrusive to everybody activity. PIC is used with Linx wireless system which used Amplitude Modulation to transmit data.

Another approach using GSM technology to communicate with the remote devices via SMS is remote monitoring system [16]. This paper illustrates a technique for remotely reading electricity meter readings using SMS. Both postpaid and prepaid are feasible to implement using this architecture as SMS based data collection can be done very quickly and efficiently.

In [17], a wireless sensor network (WSN) is used for an intelligent temperature measurement system. In the system, temperature signals are acquired by digital multipoint thermometers, and transmitted to the advanced RISC microprocessor (ARM) by using Wireless Fidelity (WiFi) technology. Then they are stored in SD card which is controlled by the microprocessor according to the IIS-bus standard format. The software design of data acquisition is completed in this paper. The progress of transplanting Linux operating system to the ARM hardware platform is described, and the driver programs of SD card and SD WiFi device are developed based on Linux operating system and SD card agreement. A special data storage file system is accomplished for reading and writing SD card, as well as managing of the data file by the FAT16 file system. At last, the function of man-machine interaction is accomplished.

Wireless sensor networks in home are easy to establish without using cables and offers a greater coverage. There are a number of studies which says

that Wireless sensor networks are a cost effective solution for collecting, receiving and transmitting data. A RF based Weather monitoring System is proposed in [18]. It describes about measuring pressure, temperature and humidity in the atmosphere for up to date weather monitoring-Weather is monitored at different levels of the atmosphere, by using an hydrogen balloon in which pressure, temperature and humidity sensors are embedded .These measured values are then transmitted to the ground station for display. Radio frequency signals are used for communication between ground station and balloon floating station (space station) respectively. [19] proposed a PIC microcontroller based instrumentation is developed for measuring the changes of linear micrometer that represents the stem diameter changes. The strain gauge is used as a sensor to detect the changes in micrometer for every $1 \mu \mathrm{m}$ changes. In addition, digital multimeter and digital oscilloscope are used for comparison and validation of the proposed PIC. More accurate reading is obtained using double strain gauges as compared to single gauges. He also concluded that this proposed system based on PIC performed better for detection and recording of changes in strain gauge as compared to multimeter or oscilloscope. Rajeev G Vishwakarma et. al. [23] described the development of an embedded device which can control up to 8 devices by sending a specific SMS message from a cell-phine. This controller is extremely handy at places for controlling the ON and OFF switching of the devices.

[21] proposed a hybrid and adaptive Maximum Peak Power Tracking (MPPT) Algorithm to track the peak power delivered by a solar panel under partial shading and fast changing environmental conditions to maximize the solar energy harvested from the Photovoltaic modules. The simulation results of MATLAB and PSpice have been compared with earlier methods. Improvements in the starting characteristic performance, tracking effect and the other undesired effects of the shadows like the avoidance of multiple maxima have been obtained. Finally attempt is made to propose a wireless Photovoltaic based irrigation system using MSP430 microcontroller as it enables system to simultaneously interface to analog signals, sensors and digital components while consuming ultra-low power. Tracking the maximum power point (MPP) of a photovoltaic array is an essential part of a photovoltaic (PV) system. PV system performance average losses are of about $20 \%-25 \%$ in electricity production. The causes are mismatching losses, partial shadows, variations in current - voltage characteristics of PV modules due to manufacturing processes, differences in the orientations and inclinations of solar surfaces, and temperature effects.

\section{Processor Used}

There is an exhaustive list of processors used in embedded systems. Different processors are used with different 
technologies and there are few systems where different processors are used for the same technology

uses JN5121 which enable users to implement IEEE802.15.4 or ZigBee compliant systems with minimum time to market and at the lowest cost

[18] [23] have implemented their designs using 8-bit microcontrollers compatible with 8051 family. These processors do not have an ADC on chip so ADC is connected externally in these designs.

uses 16-bit Intel 80C196KC microcontroller.

[20] uses 8-bit PIC microcontrollers which have on chip ADC. PIC controllers also integrates a number of system level functions, this would significantly reduce the component count, board area and system cost.

[21] uses 16-bit MSP 430 (mixed signal processing) microcontroller with ultra-low power RISC mixed-signal microprocessors. Its peripheral circuits include Liquid crystal display, keyboard functions, A/D converter and so on and it is suitable for usage fields needing extremely low power consumptions. [15] [20] have implemented their designs using 8bit PIC processors with reprogrammable flash memory. It also has $\mathrm{A} / \mathrm{D}$ converter inbuilt in the chip itself.

[12] used STC12C5A32S2 which is a single-chip microcontroller based on a high performance architecture 80C51.

\section{ANALYSIS OF EXISTING SYSTEMS}

All these systems [2]-[23] are well suited for remote control and monitoring depending upon the requirements. PC based technology is explained in [2] [3] [11] [16] [20]. In this system, $\mathrm{PC}$ is the remote monitoring station and microcontroller is the controlling device. Although one can monitor and control devices remotely from any part of the world provided internet access is available, this system incurs additional cost due to the requirement of a computer. Special hardware and software installation is required to control the devices. Also in case of power failure, it is difficult to monitor and control the status of devices unless you have a battery backup which is an additional cost.

Bluetooth based solutions are also used for this purpose [5] [7] [8] [9]. Although Bluetooth eliminates the usage cost of the network to a great extent, its range of operation is limited to a few meters. One cannot remotely monitor and control devices using this technology. Also it is desirable for each home device to have a dedicated Bluetooth module but due to the fiscal expense of this type of implementation, a single module is shared by several devices which has a disadvantage of access delay. Interference is also a problem when using this technology.

An carbon dioxide control and monitoring system is configured in [12] uses PC based monitoring system.

[13] [16] are examples of GSM based remote monitoring and control systems where the monitoring and control unit is PC. It can provide the real time data and information with the help of internet access but again requirement of PC incurs additional implementation cost and it also restricts the mobility of the user. The systems where both PC and Mobile act as monitoring and control unit are given in [7] [8] [9] and [21]. PC acts as home monitoring station and mobile control everything remotely. Although these systems eliminates one of

the drawback of real time monitoring using internet and WSN but again increased fiscal cost due to PC is again a drawback.

Another GSM based technology used for these remote monitoring and control systems is Zigbee protocol [2]. It provides easy wireless installation of

sensors at a lower cost and also increases reliability using mesh networks. Although Zigbee has a capability of $250 \mathrm{kbps}$ which is more than enough for SMS, it is not intended for voice and data streaming because it consumes too much bandwidth and drains power quickly, thereby making it unsuitable for real time applications. Also is difficult to develop with limited coverage and cost of implementation is also quite high.

From the above discussion it is concluded that designing a remote monitoring and control system that satisfies all the parameters simultaneously is a complicated task. Each proposed methodology has its own merits and demerits. However, there is still a possibility of designing a cost effective system which has an improved performance in most of the respects that will work optimally in many different applications. A new GSM-Bluetooth based Remote Monitoring and Control System with Automatic Irrigation System is proposed in this paper. Next section explains the design of the proposed system. 
Table 1

Classification of Existing Remote Monitoring and Control Systems

\begin{tabular}{|c|c|c|c|c|c|c|}
\hline References & Technology & $\begin{array}{c}\text { Main MCU } \\
\text { System }\end{array}$ & $\begin{array}{c}\text { Monitoring } \\
\text { Station }\end{array}$ & $\begin{array}{c}\text { Modules } \\
\text { Interfaced }\end{array}$ & Tools & $\begin{array}{l}\text { Programming } \\
\text { Code }\end{array}$ \\
\hline [2] & Zigbee & JN5121 & $\mathrm{PC}$ & RS232 & Keil IDE & $\begin{array}{l}\text { Java, } \\
\text { Interactive C }\end{array}$ \\
\hline [3] & Internet & $\begin{array}{l}\text { Intel } \\
80 \mathrm{C} 196 \mathrm{KC}\end{array}$ & $\overline{\mathrm{PC}}$ & None & Keil IDE & C51 \\
\hline [5] & Bluetooth & Atmega64 & $\mathrm{PC}$ & TDK Blu2i & AVR Studio & $\mathrm{C}$ \\
\hline [7] & Bluetooth & Atmega168 & Mobile & $\begin{array}{l}\text { Bluegiga } \\
\text { WT11 }\end{array}$ & $\begin{array}{l}\text { AVR Studio, } \\
\text { Symbian OS }\end{array}$ & $\begin{array}{l}\text { Interactive } \\
\text { Pythan }\end{array}$ \\
\hline [9] [8] & Bluetooth & $\begin{array}{l}\text { AVR } \\
\text { Atmega32 }\end{array}$ & Mobile & $\begin{array}{l}\text { CBOEMSPA } \\
312\end{array}$ & $\begin{array}{l}\text { AVR studio, } \\
\text { Eclipse } 3.2 .2\end{array}$ & C, Java \\
\hline [11] & RF & PIC18F452 & $\mathrm{PC}$ & $\begin{array}{l}\text { Sony Ericsson } \\
\text { GM47 }\end{array}$ & ValCon & $\begin{array}{l}\text { Visual C Net } \\
2008 \text { editor }\end{array}$ \\
\hline [12] & Fuzzy logic & $\begin{array}{l}\text { STC12C5A32 } \\
\text { S2 }\end{array}$ & $\mathrm{PC}$ & $\begin{array}{l}\text { STC12C5608, } \\
\text { STC12C5608 } \\
\text { AD }\end{array}$ & FuzzyCOPE & $\mathrm{C} / \mathrm{C}++$ \\
\hline$[13]$ & GSM & MSP430F149 & $\mathrm{PC}$ & $\begin{array}{l}\text { Siemens } \\
\text { TC35 }\end{array}$ & C430 IDE & $\mathrm{C}$ \\
\hline [14] & GPRS & C8051F310 & PC, Mobile & CC1020 & GPRS Module & Python \\
\hline [15] & GSM-WSN & $\begin{array}{l}\text { PIC16F74 } \\
\text { (DIP } \\
\text { configuration) }\end{array}$ & PC, Mobile & $\begin{array}{l}\text { Linx TXM \& } \\
\text { RXM-315-LR }\end{array}$ & $\begin{array}{l}\text { AVR Studio, } \\
\text { MPLAB IDE }\end{array}$ & $\bar{C}$ \\
\hline$[16]$ & $\overline{\text { GSM }}$ & 8051 family & $\mathrm{PC}$ & Nokia FBUS & $\begin{array}{l}\text { Keil IDE, } \\
\text { Linux OS }\end{array}$ & C, Java \\
\hline [17] & Wi-Fi & $\overline{A R M}$ & PC, Mobile & $\begin{array}{l}\text { Siemens } \\
\text { TC35, } \\
\text { CC1100 }\end{array}$ & $\begin{array}{l}\text { Keil IDE, } \\
\text { Linux OS }\end{array}$ & C51 \\
\hline [18] & GSM-WSN & 8051 family & PC, Mobile & $\begin{array}{l}\text { Siemens } \\
\text { TC35, } \\
\text { CC1100 }\end{array}$ & Keil IDE & C51 \\
\hline [20] & WSN & PIC16F877 & $\mathrm{PC}$ & LCD & $\begin{array}{l}\text { IDE \& } \\
\text { MikroC } \\
\text { compiler } \\
\end{array}$ & MikroC \\
\hline$[21]$ & $\begin{array}{l}\text { Photovoltaic } \\
\text { system }\end{array}$ & MSP430 & Mobile & $\begin{array}{l}\text { GM862QUA } \\
\text { D-PY, } \\
\text { CC2430 }\end{array}$ & $\begin{array}{l}\text { MATLAB } \\
\text { and PSpice }\end{array}$ & C, Pythan \\
\hline [23] & GSM-WSN & 8051 family & PC, Mobile & $\begin{array}{l}\text { Siemens } \\
\text { TC35, } \\
\text { CC1100 }\end{array}$ & Keil IDE & $\mathrm{C} 51$ \\
\hline
\end{tabular}




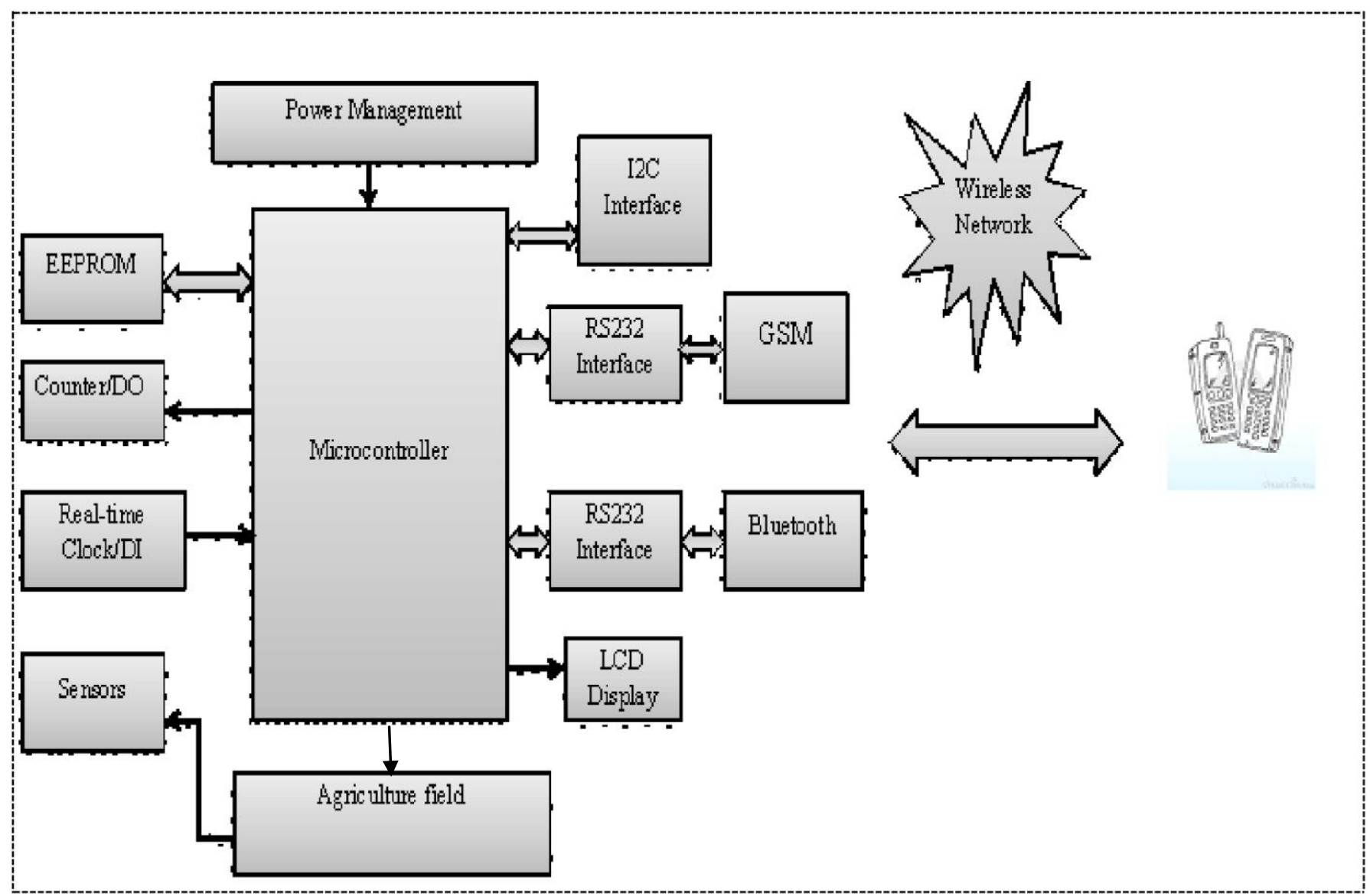

Fig 1. Block Diagram of Remote Monitoring and Control System with Automatic Irrigation system using GSM-Bluetooth

\section{IV. \\ SYSTEM}

The block diagram of the proposed GSM-Bluetooth based system is given in fig. 1. In this system both GSM and Bluetooth modules are interfaced with the main controller chip. GSM is used for remotely monitoring and controlling the devices via a mobile phone by sending and receiving SMS via GSM network. Bluetooth is used for the same purpose but within a range of few meters, say when user is inside the periphery of the building where the system is installed, Bluetooth can be used for communicating with the devices thereby eliminating the network usage cost. This is an important merit of the proposed system. The motor pumps and fans are controlled automatically using sensor and the other appliances are controlled by Bluetooth or GSM network via SMS. The system informs user about any abnormal conditions like low water detection and temperature rise via SMS from the GSM Module to the user's mobile and actions are taken accordingly by the user. This leads to efficient utilization of power. Even using Bluetooth module, by SMS, pump and fan could be automatically ON or OFF.

\section{System Architecture}

The hardware of the system mainly includes a 8-bit microcontroller chip, a GSM module, a Bluetooth module and RS232 interfaces. The microcontroller is interfaced with different sensors for controlling different applications. Moisture sensor is used to sense the moisture of soil moisure, Temperature sensor detects the temperature, $\mathrm{CO} 2$ gas sensor detects $\mathrm{CO} 2$ concentration and Humidity sensor Humidity in analog form. The analog data from temperature sensor and Humidity sensor is converted to digital using A/D converter. EEPROM is used for recording the data provided by the sensors. It provides this data to the microcontroller for analysis when requested and an alarm is raised in emergency conditions depending upon this data and an SMS is send to the user's mobile. Even routinely recorded these data can help in making remote and control module of automatic irrigation system. Blutooth module provides free cost control over irrigation system. GSM provide distance based control over irrigation parameters. 
Real time clock/calendar helps in proper day-to-day recording of data. The measured values and the state of the devices are displayed on the LCD. The GSM and Bluetooth modules which are the most important part of this system are interfaced with the microcontroller using a RS232 interface. The modules act like an interface between the controller and GSM network. The GSM module must have a SIM (Subscriber Identity Module) card to make the network identify the user. The microcontroller communicates with the GSM module using the AT commands. These AT commands are used to send and receive SMS. The programming code for the microcontroller is written in some high level language. When a user sends an SMS requesting the status of devices and measured value by the sensors, the GSM module sends the data stored in EEPROM as a response via SMS. The use of a mobile as a monitoring and control station provides for mobility in the proposed system is an important backbone of all the existing internet based systems.

\section{CONCLUSION AND FUTURE WORK}

Detail survey of various remote monitoring and control systems have been presented along with the classification based on various parameters and the design of a GSM-Bluetooth based remote monitoring and control system with Automatic irrigation system has been proposed. This system has an advantage of using both GSM and Bluetooth technology which thereby eliminates the cost of network usage to a great extent by using Bluetooth when in the range of few meters with the devices. The system is scalable and allows any number of different devices to be added with no major changes in its core. But it is not efficient in situations which have strong real time requirements. The system has its application in situations where the amount of data to be transferred is mandatory. The study and literature survey based on research papers is proposed in this paper which helps in adopting best

suited deployment of system according to feature's requirement. Implementation on above subject will be processed in future work.

\section{VI.REFERENCES}

[1] Yiming Zhou, Xianglong Yang, Wang, L., Yibin Ying Sch. of Biosystems Eng. \& Food Sci., Zhejiang Univ., Hangzhou, "A Wireless Design of Low-Cost Irrigation System Using ZigBee Technology", IEEE 2009 International Conference on Networks Security, Wireless Communications and Trusted Computing, vol. 1, pp.572 - 575. 2009.

[2] Shen Jin, Song Jingling, Han Qiuyan, Wang Shengde, Yang Yan, School of Electric and Electronic Engineering, "A Remote Measurement and Control System for Greenhouse Based on GSM-SMS" IEEE 8th International Conference on Electronic Measurement and Instrument, 2007.

[3] [4] Arrouf,

$$
\text { [5] M [6] Benabi }
$$

$$
\text { d, [7] F. }
$$

[8] Mebarki [9]

[10] "Photovoltaic pumping system based on Intel 80C196KC microcontroller" IEEE 10th International Conference on Environment and Electrical Engineering, pp. 1-5, May 2011.

[11] G. K. Banerjee, Rahul Singhal, Bhubaneswar, Orissa India "Microcontroller Based Polyhouse Automation Controller", International Symposium on Electronic System Design, pp. 158-162, Dec 2010.

[12] Bhutada, S.; Shetty, S.; Malye, R.; Sharma, V.; Menon, S.; Ramamoorthy, R, "Implementation of a fully automated greenhouse using SCADA tool like LabVIEW", International conference on Advanced Intelligent Mechatronics. Proceedings, pp. 741-746, 2005.
[13] Wenbin Huang, Guanglong Wang, Jianglei Lu, Fengqi Gao, Jianhui Chen "Research of wireless sensor networks for an intelligent measurement system based on ARM", International conference on Mechatronics and Automation Conference on, pp. 1074 - 1079, 2011.

[14] Healy, M. Newe, T. Lewis "Wireless Sensor Node hardware: A review", IEEE 15th International Symposium on Consumer Electronics, pp. 621-624, 2011.

[15] Ahmed, V. , " Innovative cost effective approach fro cell phone based remote controlled embedded system for irrigation", International Conference on Communication Systems and Network Technologies, 2011, pp. 419-144, 2011.

[16] Vasif Ahmed and Siddharth A. Ladhake; "Design of ultra low cost cell phone based embedded system for irrigation"; IEEE Transactions on Consumer Electronics, 2010 , Vol. 55, No. 2 , pp. 718-721.

[17] I.F. Akyildiz, W. Su, Y. Sankarasubramaniam, E.Cayirci , "Wireless sensor networks: a survey", IEEE Transactions on Consumer Electronics, vol. 44, pp. 1291-1297, Aug 2002.

[18] Mahir Dursun, Semih Ozden; "A prototype of PC based control of irrigation" International conference on Environmental Engineering and Applications, vol. 50, pp. s255-258, Nov. 2010.

[19] Ma Shuying, Ma Yuquan, Chen Lidong, Liu Shiguang, "Design of a new measurement and control system of $\mathrm{CO} 2$ for greenhouse based on fuzzy control", International Conference on Computer and Communication Technologies in agriculture engneering 2010, pp 128-131, May 2008.

[20] Chen Peijiang; Jiang Xuehua; "Design and Implementation of Remote Monitoring System Based on GSM", PacificAsia Workshop on Computational Intelligence and Industrial Application, 2008, pp. $678-681$.

[21] Yan Xijun, Lu limei, Xu Lizhong, "The Application of wireless sensor network in the Irrigation Area Automatic System", International Conference on Networks Security, Wireless Communications and Trusted Computing 2009, pp. 21-24.

[22] Jeng-Nan Juang, R. Radharamanan; "Low Cost Soil Moisture System: A Capstone Design Project", International Conference on Intelligent Computation Technology and

[23] Automation, 2010, pp. 1012-1014.

[24] Md. Wasi-ur-Rahman, Mohammad Tanvir Rahman, Tareq Hasan Khan and S.M. Lutful Kabir, "Design of an Intelligent SMS based Remote Metering System", Proceedings of the IEEE International Conference on Information and Automation, 2009, pp. 1040-1043.

[25] Yuksekkaya, B.; Kayalar, A.A.; Tosun, M.B.; Ozcan, M.K.; Alkar, A.Z.; "Research of Wireless Sensor Networks for an Intelligent Measurement System Based on ARM", IEEE Transactions on Mechatronics and Automation, Volume: 52 , Issue: 3, 2006 , pp. $837-843$.

[26] Sankar, P., Norman, S.R., "Embedded System for Monitoring Atmospheris Weather Conditions Using Weather Balloon", International Conference on Control, Automation, Communication and Energy Conservation, pp. 1-4, June 2009.

[27] N. M.Khairi, M.A. Marni, Shah Rizam M.S.B, Nooritawati Md Tahir, M.I. Naimah and H. Zainol Abidin, 
"Optimization of Strain Gauge for Stem Measurement using PIC based Instrumentation" IEEE International Conference on System Engineering and Technology, 2011, pp. 196-199.

[28] Daniel K. Fisher and Hirut Kebede "A low-cost microcontroller-based system to monitor crop temperature and water status", Computers and Electronics in Agriculture, Elsevier B.V., pp. 168-173, 2010.

[29] M D Goudar, B. P. Patil and V. Kumar, "Adaptive MPPT algorithm for a distributed wireless photovoltaic based irrigation system", International Conference on Devices and Communication, 2011.

[30] Abhinav Rajpal, Sumit Jain, Nistha Khare and Anil Kumar Shukla, "Microcontroller based Automatic Irrigation System with Moisture Sensors", Proceedings of the International Conference on Science and Engineering, 2011, pp. 94-96.

[31] Rajeev G Vishwakarma, "Wireless Solution for Irrigation in
Agriculture", Proceedings of the International Conference on Signal Processing, Communication, Computing and Networking Technologies, pp. 61-63, 2011.

[32] PIC 16F87/88 Data Sheet", Microchip Technology Inc. 2011.

[33] Dae-Young Lim; Young-Jae Ryoo, "Development of remote monitoring system for cold-storage"; 30th Annual Conference of IEEE Industrial Electronics Society, 2004; vol 3, pp-2252-2254.

[34] Zhu Qishen, Zhu Dongmei and Su Xunwen, "Distributed remote temperature monitoring and acquisition system based on CAN bus"; Prognotics and Health Management Conference, 2010, pp-1-4.

[35] Jifeng Ding, Jiyin Zhao and Biao Ma, "Remote

[36] monitoring system of Temperature and Humidity based on GSM"; 2nd International Conference on Computational Intelligence and Industrial Application, 2008; pp-678-681. 